\title{
REDESAIN FASILITAS KERJA PADA PROSES PENGAMPLASAN INDUSTRI KECIL KERAJINAN MONEL JEPARA
}

\author{
Muhammad Choiru Zulfa ${ }^{1}$, Jati Widagdo ${ }^{2}$, Gun Sudiryanto ${ }^{3}$ \\ ${ }^{1,3}$ Program Studi Teknik Industri, Fakultas Sains dan Teknologi Unisnu, Jepara \\ ${ }^{2}$ Program Studi Desain Produk, Fakultas Sains dan Teknologi Unisnu, Jepara \\ 'zulfa.ti@unisnu.ac.id, ${ }^{2}$ jati.widagdo33@gmail.com, ${ }^{3}$ gunsudiryanto@unisnu.ac.id
}

\begin{abstract}
The sanding process of monel craft in the small industry of Jepara monel handicraft operator's work position has not been taken into account. The height of the machine and the operator's seat that is not adjusted to the dimensions of the worker's body make the work position that is not ergonomic. Continuous ergonomic work postures can cause complaints in the muscoloskeletal system or muckoloskeletal disorders (MSDs). MSDs in the long run can cause health problems that also affect the quality and quantity of production. Work posture improvement begins with identifying the level of muckoloskeletal complaints. Musculoskeletal complaints assessment uses the Rappid Entire Body Assessment (REBA) and Nordic Body Map (NBM) methods. The results of muscoloskeletal complaints analysis using REBA obtained a score of 7 which means a moderate level of risk. The risk level of muscoloskeletal complaints is strengthened by the results of the NBM questionnaire with the lowest score of 47 with a high risk category so that there is a need for remedial action. The redesign of work facilities is based on Anthropometry data of workers obtained by the size of $45.8 \mathrm{~cm}$ for the height of the cushion, the width of the cushion for the seat $33 \mathrm{~cm}$, the length of the seat cushion 40 $\mathrm{cm}$, the height of the table $54.8 \mathrm{~cm}$, the width of the table $20 \mathrm{~cm}$, and the length of the table $57 \mathrm{~cm}$.
\end{abstract}

Keywords: Monel, muscoloskeletal, NBM, REBA, Anthropometry

\begin{abstract}
Abstrak
Proses pengamplasan kerajinan monel di industri kecil kerajinan monel Jepara posisi kerja operatornya belum diperhatikan kenyamananya. Ketinggian mesin dan kursi operator yang tidak disesuaikan dengan dimensi tubuh para pekerja membuat posisi kerja yang tidak ergonomis. Postur kerja tidak ergonomis yang berlangsung terus menerus dapat mengakibatkan keluhan pada sistem muscoloskeletal atau muckoloskeletal disorders (MSDs). MSDs dalam jangka panjang dapat menyebabkan permasalahan kesehatan yang juga mempengaruhi kualitas dan kuantitas produksi. Perbaikan postur kerja diawali dengan mengidentifikasi tingkat keluhan muckoloskeletal. Penilaian keluhan musculoskeletal menggunakan metode Rappid Entire Body Assesment (REBA) dan Nordic Body Map (NBM). Hasil analisa keluhan muscoloskeletal mennggunakan REBA diperoleh skor 7 yang berarti tingkat resiko sedang. Tingkat resiko keluhan muscoloskeletal diperkuat dengan hasil kuesioner NBM dengan nilai skor terendah 47 dengan kategori resiko tinggi sehingga perlu adanya tindakan perbaikan. Redesain fasilitas kerja didasarkan pada data Anthropometri para pekerja diperoleh ukuran $45,8 \mathrm{~cm}$ untuk tinggi alas duduk, lebar alas duduk $33 \mathrm{~cm}$, panjang alas duduk 40 $\mathrm{cm}$, tinggi meja $54,8 \mathrm{~cm}$, lebar meja $20 \mathrm{~cm}$, dan panjang meja $57 \mathrm{~cm}$.
\end{abstract}

Kata kunci : Monel, muscoloskeletal, NBM, REBA, Anthropometri

\section{PENDAHULUAN}

Pada proses pengamplasan dengan menggunakan mesin grinda masih terlihat bahwa posisi kerja operatornya belum diperhatikan kenyamananya. Tinggi mesin dan kursi operator yang tidak disesuaikan dengan dimensi tubuh para pekerja membuat posisi kerja yang tidak ergonomis. Para pekerja duduk pada bangku kecil dengan ketinggian alat yang hampir sejajar dengan mesin amplas, sehingga membuat posisi tubuh pekerja menjadi tidak nyaman karena harus membungkuk pada saat melakukan proses pengamplasan. Posisi leher dan punggung yang membungkuk dapat menyebabkan rasa sakit dibagian leher dan punggung. Posisi lutut 
kaki yang harus tertekuk juga dapat menyebabkan sakit pada bagian kaki. Benda kerja dipegang dengan tangan pekerja langsung berhubungan dengan mesin amplas yang dapat menyebabkan tangan tergores mesin amplas. Posisi kerja tidak ergonomis berlangsung secara statis dan berulang-ulang dapat menyebabkan keluhan berupa kerusakan sendi, ligamen, dan tendon (Jalajuwita dan Pasakarini, 2015) Keluhan musculoskeletal adalah keluhan pada bagian otot skeletal yang dirasakan seseorang mulai dari keluhan sangat ringan sampai sangat sakit. Apabila otot menerima beban statis berulang-ulang dalam jangka waktu yang lama, dapat menyebabkan keluhan yang berupa kerusakan pada sendi, ligamen dan tendon. Kerusakan pada sendi, ligamen dan tendon ini biasa disebut sebagai Repetitive Strain Injuries (RSI), Cumulatif Trauma Disorders (CTD) dan Repetitive Motion Injuries (RMI) (singh, dkk, 2014). Menurut penelitian Pram Eliyah Y. dan Sri Rahayu (2011) diperoleh kesimpulan bahwa posisi duduk adalah posisi yang terbaik untuk melakukan pekerjaan menggerinda jika dibandingkan dengan posisi yang lainnya. Selain itu posisi duduk dapat mengurangi rasa sakit yang berlebihan pada tulang belakang yang menyebabkan kerusakan pada tulang belakang atau lumbar sehingga dipelukan rancangan model dan ukuran kursi yang disesuiakan dengan meja kerja.
Untuk menciptakan kondisi kerja yang aman, nyaman dan berkualitas perlu dilakukan analisis evaluasi ergonomi untuk mengetahui tingkat resiko ergonomi para pengrajin monel khususnya pada proses pengamplasan. Selain itu perlu adanya rancangan desain fasilitas kerja proses pengamplasan berupa meja mesin grinda dan kursi kerja yang ergonomis untuk menciptakan kenyamanan dan mengurangi keluhan otot skeletal yang dialami oleh operator.

\section{METODE PENELITIAN \\ Subyek Penelitian}

Subyek penelitian ini adalah pekerja proses pengamplasan kerajinan monel di UKM milik Bapak Muhlisin yang beralamat di desa Robayan Kecamatan Kalinyamatan Kabupaten Jepara.

\section{Instrumen Penelitian}

Instrumen penelitian yang digunakan pada penelitian ini adalah :

a. Kuesioner Nordic Body Map (NBM) Kuesioner Nordic Body Map digunakan untuk mengetahui bagian otot yang mengalami keluhan dengan tingkat keluhan mulai dari rasa agak sakit sampai sangat sakit. Hasil analisis peta tubuh NBM dapat diestimasi jenis dan tingkat keluhan otot skeletal yang pekerja rasakan. (Tarwaka, 2015). Kuesioner NBM yang digunakan dapa penelitian ini dapat dilihat pada Gambar 1. 


\begin{tabular}{|l|l|l|l|l|l|l|l|l|}
\hline \multicolumn{9}{|c|}{ NBM } \\
(NORDIC BODY MAP)
\end{tabular}

Gambar 1. Kuesioner Nordic Body Map

Sumber : Tarwaka, dkk, 2015, Ergonomi untuk Keselamatan, Kesehatan Kerja dan

Produktivitas, Harapan Press: Surakarta.

b. Rapid Entire Body Assesment (REBA) Rappid Entire Body Assesment adalah alat analisis untuk memberikan pengamatan terhadap postur kerja yang cepat dan mudah, selain itu REBA juga merupakan alat analisis untuk kegiatan statis dan dinamis serta dapat memberikan tingkat tindakan resiko terhadap keluhan muskuloskeletal (Qutubudin dan Quma, 2013). Adapun bentuk lembar kerja REBA dapat dilihat pada Gambar 2. 


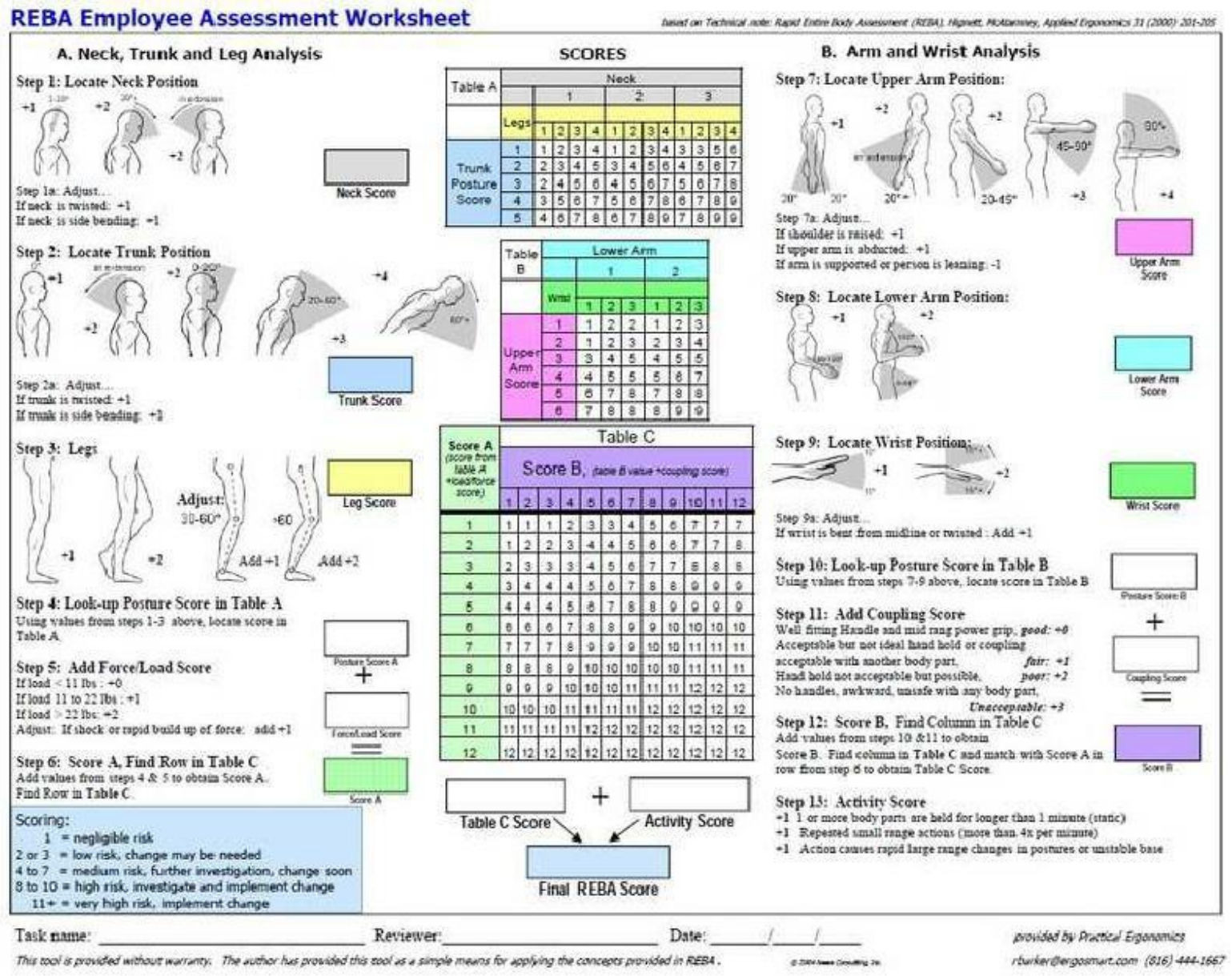

Gambar 2. Lembar Kerja REBA

\section{Anthropometri}

Istilah Anthropometri berasal dari bahasa Yunani terdiri dari dari kata "anthropos" yang berarti manusia dan "metrikos" yang berarti pengukuran. Dengan demikian anthropometri dapat diartikan studi tentang variasi statistik dimensi tubuh manusia dan implikasinya pada desain (Cecilia Berlin and Caroline Adams, 2016). Anthropometri sangat penting untuk diperhatikan terutama dalam mendesain tempat kerja. Hal ini dikarenakan ukuran tubuh dan bentuk manusia yang mempunyai banyak varibilitas. Selain itu jenis kelamin, ras/suku dan jenis pekerjaan juga mempengaruhi dalam perancangan sederhana (I Wayan Sukania dan Verry Sentosa, 2010).

Sikap dan posisi tubuh dalam bekerja ditentukan oleh jenis pekerjaan yang dilakukan. Masing-masing posisi kerja mempunyai pengaruh yang berbeda-beda terhadap tubuh. Prinsip perancangan menggunakan data anthropometri sebagai berikut (I Wayan Sukania dan Verry Sentosa, 2010):

1. Prinsip perancangan produk bagi individu dengan ukuran yang ekstrim.

2. Prinsip perancangan produk yang bisa dioperasikan diantara rentang ukuran tertentu.

3. Prinsip perancangan produk dengan ukuran rata-rata

\section{HASIL DAN PEMBAHASAN \\ Tingkat Keluhan Muskoloskeletal}

Tingkat keluhan muskoloskeletal yang dirasakan oleh para pekerja terlebih dahulu diukur menggunakan kuesioner NBM. Kuesioner NBM diberikan kepada 5 pekerja proses pengamplasan. Hasil rekapitulasi kuesioner NBM disajikan pada Tabel 1. 
Tabel 1. Rekapitulasi Kuisioner NBM

\begin{tabular}{|c|l|c|l|}
\hline No & Nama Pekerja & Total Skor & Tingkat Resiko \\
\hline 1 & Rokhim & 47 & Tinggi (diperlukan tindakan segera) \\
\hline 2 & Agus Salim & 54 & Tinggi (diperlukan tindakan segera) \\
\hline 3 & Ridwan & 54 & Tinggi (diperlukan tindakan segera) \\
\hline 4 & Zakki & 57 & Tinggi (diperlukan tindakan segera) \\
\hline 5 & Subkhan & 48 & Tinggi (diperlukan tindakan segera) \\
\hline
\end{tabular}

Skor REBA

Tingkat keluhan muskoloskeletal selanjutnya dianalisis menggunakan lembar kerja REBA. Hasil analisis REBA pada beberapa posisi kerja para pekerja proses pengamplasan dapat dilihat pada Tabel 2.

Tabel 2. Rekapitulasi Skor REBA

\begin{tabular}{|c|c|c|c|c|}
\hline Postur Kerja & Skor REBA & Tingkat Resiko & Kategori Resiko & Tindakan \\
\hline $\mathbf{1}$ & 7 & 2 & Sedang & Perlu adanya tindakan \\
\hline $\mathbf{2}$ & 5 & 2 & Sedang & Perlu adanya tindakan \\
\hline $\mathbf{3}$ & 7 & 2 & Sedang & Perlu adanya tindakan \\
\hline
\end{tabular}

\section{Data Anthropometri Redesain Fasilitas}

Kerja

Untuk menentukan ukuran fasilitas kerja baru diperlukan data anthropometri tubuh para pekerja. Dari hasil pengukuran dan pengolahan data anthropometri yang terdapat pada Lampiran 3 diperoleh persentil ukuran data anthropometri pada Tabel 3.

Tabel 3. Hasil Pengolahan Data Anthropometri

\begin{tabular}{|c|l|c|c|c|c|c|}
\hline \multirow{2}{*}{ No } & \multicolumn{1}{|c|}{ Dimensi } & \multirow{2}{*}{ Rata-Rata (cm) } & \multirow{2}{*}{ Standar Deviasi } & \multicolumn{3}{|c|}{ Persentil } \\
\cline { 5 - 7 } & & & & 5 & 50 & 95 \\
\hline $\mathbf{1}$ & Tinggi Popliteal & 48.8 & 2.280351 & 45.8 & 49 & 50.8 \\
\hline $\mathbf{2}$ & Pantat Popliteal & 40.8 & 4.32435 & 37.2 & 40 & 46.6 \\
\hline $\mathbf{3}$ & Lebar Pantat & 33 & 2.915476 & 29.6 & 33 & 36.4 \\
\hline $\mathbf{4}$ & Tinggi Siku Duduk & 24 & 1.224745 & 23 & 24 & 25.6 \\
\hline $\mathbf{5}$ & Jangkauan Tangan & 60.2 & 2.683282 & 58 & 59 & 63.6 \\
\hline $\mathbf{6}$ & Lebar Bahu & 56.2 & 3.03315 & 53 & 57 & 59 \\
\hline
\end{tabular}

\section{Desain Fasilitas Kerja Proses Pengamplasan}

Para pekerja proses pengamplasan kerajinan monel di UKM Bapak muhlisin berdasarkan kuesioner NBM dan Skor REBA mempunyai tingkat resiko yang tinggi. Oleh sebab itu, perlu dilakukan redesain fasilitas kerja yang disesuaikan dengan dimensi tubuh pekerja. Fasilitas kerja yang akan diperbaiki meliputi kursi kerja, meja kerja, dan pegangan benda kerja. Berdasarkan hasil analisis peneliti menentukan spesifikasi desain fasilitas kerja baru yang terlihat pada Tabel 4 .

Tabel 4. Spesifikasi Ukuran Desain Fasilitas Kerja

\begin{tabular}{|c|c|c|}
\hline No & Objek & Ukuran \\
\hline $\mathbf{1}$ & Tinggi Alas Duduk & $45.8 \mathrm{~cm}$ \\
\hline $\mathbf{2}$ & Lebar Alas Duduk & $33 \mathrm{~cm}$ \\
\hline $\mathbf{3}$ & Panjang Alas Duduk & $40 \mathrm{~cm}$ \\
\hline $\mathbf{4}$ & Tinggi Meja & $54.8 \mathrm{~cm}$ \\
\hline $\mathbf{5}$ & Lebar Meja & $20 \mathrm{~cm}$ \\
\hline $\mathbf{6}$ & Panjang Meja & $57 \mathrm{~cm}$ \\
\hline
\end{tabular}


Setelah diperoleh spesifikasi ukuran faslilitas kerja, selanjutnya dibuat gambar rancangan fasilitas kerja baru dengan menggunakan software autocad 2016. Gambar bagian-bagian fasilitas kerja dapat dilihat pada Gambar 3.

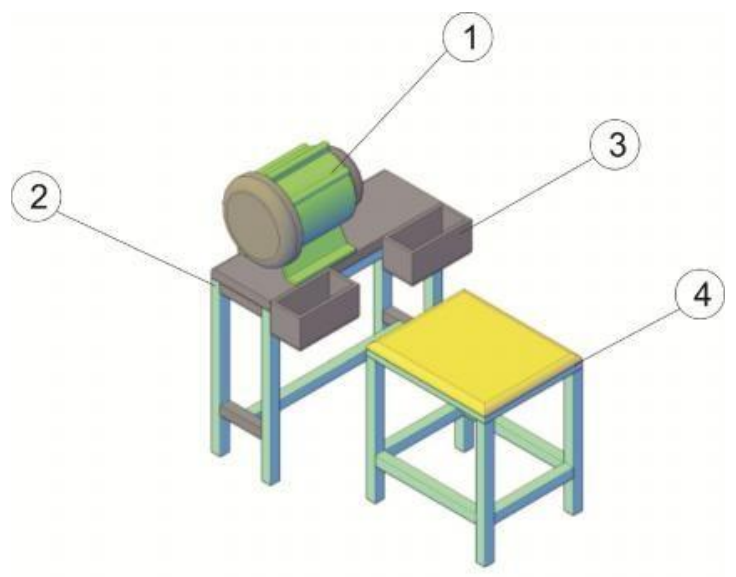

Keterangan :

1. Mesin Gerinda

2. Meja Kerja

3. Tempat benda kerja

4. Kursi Kerja

Gambar 3. Bagian-Bagian Fasilitas Kerja

\section{SIMPULAN}

Dari hasil pengolahan data yang sudah diperoleh dapat disimpulkan bahwa :

1. Tingkat keluhan muskoloskeletal berdasarkan skor REBA proses pengamplasan kerajinan monel pada kerajianan monel termasuk kategori sedang sehingga perlu tindakan segera. $\mathrm{Hal}$ ini diperkuat dengan hasil kuisioner NBM yang menyebutkan bahwa tingkat keluhan muskoloskeletal pada proses pengamplasan kerajinan monel mempunyai tingkat resiko tinggi.

2. Untuk mengurangi tingkat keluhan muskoloskeletal perlu diadakan tindakan berupa perbaikan fasilitas kerja dengan memperhatikan dimensi tubuh para pekerja sehingga dapat diperoleh faslitas kerja yang ergonomis.

3. Redesain fasilitas kerja didasarkan pada data Anthropometri para pekerja dengan spesifikasi ukuran yaitu $45,8 \mathrm{~cm}$ untuk tinggi alas duduk, lebar alas duduk 33 $\mathrm{cm}$, panjang alas duduk $40 \mathrm{~cm}$, tinggi meja $54,8 \mathrm{~cm}$, lebar meja $20 \mathrm{~cm}$, dan panjang meja $57 \mathrm{~cm}$.

\section{SARAN}

1. Perlu dilakukan penelitian lebih lanjut tentang kesehatan kerja yang berkaitan dengan lingkungan kerja.

2. Perlu dilakukan penelitian lebih lanjut tentang kualitas dan kuantitas produk yang dihasilkan agar redesain dapat diaplikasikan.

\section{DAFTAR PUSTAKA}

Berlin, Cecilia dan Caroline Adams. 2016. Production Ergonomics : Designing Work Systems to Support Optimal Human Performance. London : Ubiquity Press

Jalajuwita, Rovanaya Nurhayuning dan Indriati Paskarini. 2015. Hubungan Posisi Kerja Dengan Keluhan Muskuloskeletal Pada Unit Pengelasan PT. X Bekasi. The Indonesian Journal of Occupational Safety and Health, Vol. 4, No. 1 JanJun 2015: 33-42

Qutubuddin dan A,G,S Kuma. 2013. Ergonomic Evaluation of Tasks Performed by Workers in Manual Brick in Karnataka, India. Global Journal of Researches in Engineering vol 13 p3542. India : Global Journal inc

Singh, Er Surinder, dkk. 2013. A Proposed REBA on Small Scale Forging Industry. Journal of Modern Engineering Reaserch vol 3 pp -37963802. India : CT group of institutions

Sukania, I Wayan dan Verry Sentosa. 2010. Aspek Ergonomi Dalam Perbaikan Rancangan Fasilitas Pembuat Cetakan Pasir di PT X. Seminar Nasional Tahunan Teknik Mesin (SNTTM) ke-9 Palembang, 13-15 Oktober 2010

Tarwaka, dkk. 2015. Ergonomi untuk Keselamatan, Kesehatan Kerja dan Produktivitas. Harapan Press: Surakarta.

Wignjosoebroto, Sritomo, 2001, Ergonomi, Studi Gerak Dan Waktu : Teknik Analisis untuk Peningkatan Produksi, Guna Widya, Surabaya. 
Yuliana, Pram Eliyah dan Sri Rahayu. 2011. Perancangan Fasilitas Grinding Untuk Laboratorium. Prosiding Konferensi Nasional Idea Tech "Inovasi dalam Desain dan Teknologi" Sekolah Tinggi Teknologi Surabaya 